Motrivivência Ano XXI, No 32/33, P. 258-279 Jun-Dez./2009

\title{
CONTEÚDOS DE EDUCAÇÃO FÍSICA: percepções dos professores da rede
}

Larissa Beraldo Kawashima'

\begin{abstract}
Resumo Abstract
A pesquisa tem por finalidade identificar como os professores de Educação Física sistematizam os conteúdos para o $1^{\circ}$ e $2^{\circ}$ ciclo do ensino fundamental, compreendendo como ocorre a construção deste saber em seus planejamentos. A pesquisa é de natureza qualitativa e conta com a participação de 11 professores de Educação Física da rede municipal de Cuiabá-MT. De modo geral, ao atrelar todos os conteúdos trabalhados pelos professores pesquisados, temos como resultado um trabalho sistematizado para as séries iniciais, com conteúdos diversificados e específicos para cada ciclo. Mas, individualmente, cada professor precisa complementar seu trabalho, oferecendo outros conteúdos não trabalhados.

The research aims to identify how the physical education teachers systematize the class contents for the $1 \mathrm{st}$ and 2 nd cycle of basic education, understanding how the construction of this knowledge in their planning works. It is a qualitative research with the participation of 11 physical education teachers from Cuiabá, Mato Grosso State. In general, the joinning of all contents worked by the teachers results is a systematic work for the inicial grades, with several and specific contents for each cycle. But individually, each teacher needs to supplement their work by offering other content not worked.
\end{abstract}

Palavras-chaves: Conteúdos; Sistematização; Séries iniciais.

Keywords: Contents; Systematization; Initial series.

1 Mestre em Educação - IE - UFMT. Instituto Federal de Educação, Ciência e Tecnologia de Mato Grosso - IFMT Contato: lalabeka@hotmail.com 
Ano XXI, n 32/33, junho e dezembro/2009

\section{Introdução}

A Lei de Diretrizes e Bases da Educação Nacional no 9.394/96 afirma que "a Educação Física, integrada à proposta pedagógica da escola, é componente curricular da Educação Básica, ajustando-se às faixas etárias e às condições da população escolar (...)" (BRASIL, 1996). Em alteração ao artigo anterior, a lei 10.793 acrescenta o termo "obrigatório" ao texto original, tornando a Educação Física "componente curricular obrigatório" da Educação Básica (BRASIL, 2003).

Assim, subentende-se que a Educação Física, como as demais disciplinas, têm conteúdos específicos. O que são conteúdos? E quais são esses conteúdos? Como são organizados e distribuídos ao longo das diferentes fases da educação básica?

Para Libâneo (2002, p.15), os elementos constitutivos dos conteúdos de ensino referem-se aos conhecimentos sistematizados, selecionados das bases das ciências e dos modos de ação acumulados pela experiência social da humanidade e organizados para serem ensinados na escola; são habilidades e hábitos, vinculados aos conhecimentos, incluindo métodos e procedimentos de aprendizagem e de estudo; são atitudes, convicções, valores, envolvendo modos de agir, de sentir e de enfrentar o mundo.
Zabala (1998) alerta que o termo "conteúdos" normalmente foi utilizado para expressar aquilo que se deve aprender, porém em relação quase exclusiva aos conhecimentos das disciplinas clássicas, quase sempre fazendo alusão a nomes, conceitos, teoremas e enunciados. Coll e colaboradores (2000) nos alerta assim que os conteúdos devem ser propostos segundo três dimensões correspondentes ao "saber fazer" (procedimentos), aos "fatos e conceitos" (conceituais) e as "atitudes, valores e normas" (atitudinais).

O objetivo desta pesquisa é identificar como os professores de Educação Física sistematizam os conteúdos para o $1^{\circ}$ e $2^{\circ}$ ciclo do ensino fundamental, compreendendo como ocorre a construção deste saber em seus planejamentos anuais e semanais.

\section{Metodologia}

A pesquisa é de natureza qualitativa-interpretativa e conta com a participação de 11 professores de Educação Física da rede municipal de Cuiabá-MT, atuantes no $1^{\circ}$ e $2^{\circ}$ ciclos do ensino fundamental de 6 escolas. Os dados foram coletados através de documentos, no caso, planejamentos anuais e semanais de cada professor. As escolas são nomeadas de E1 a E6, sendo os professores identificados 
pelas iniciais de seus nomes, idade e escola em que trabalha.

\section{Análise e discussão dos dados}

Os conteúdos explicitados pelos professores serão agrupados em blocos, sendo que em alguns momentos houve a indicação do professor quanto à classificação dos mesmos e, em outros momentos, não. Nos planejamentos dos professores não aparece classificação dos conteúdos em suas dimensões. A relação estabelecida dos conteúdos com suas dimensões foram realizadas pela autora, a fim de demonstrar que, mesmo não aparecendo esta classificação nos planejamentos analisados, os professores conhecem e trabalham (ou não) com as três dimensões.

\section{"Conhecimento de si" - o corpo e suas possibilidades de movimento}

A Educação Física, na rede municipal de Cuiabá, está inserida na área de Linguagens, e segundo Neira (2007, p. 14) o corpo é entendido como suporte de linguagem que manifesta a cultura em que está inserido, ou seja, "ao se movimentarem homens e mulheres expressam intencionalidades, comunicam e veiculam modos de ser, pensar e agir característicos, ou seja, culturalmente impressos em seus corpos".

Neste sentido, entende-se o corpo como um suporte textual onde se inscrevem a história e a trajetória dos homens e da cultura. Com mais esta justificativa e compreendendo o corpo como "texto da cultura" e os gestos os "textos do corpo" - expressões de Neira (2007) - resolveu-se iniciar as análises por este bloco de conteúdos.

Os conteúdos relacionados à psicologia e psicomotricidade estão presentes em todos os planejamentos analisados dos professores de Educação Física, seja como conteúdos para todos os ciclos, sejam específicos para algumas etapas, mas sempre presentes. Estes conteúdos são propostos apenas na dimensão procedimental, sendo eles assim apresentados pelos professores de Educação Física: Esquema corporal: partes do corpo; Coordenação motora fina e grossa: coordenação dinâmica global (ampla), coordenação manual e coordenação visomotora; Lateralidade; Orientação espacial e temporal; Percepção (espacial, temporal e tátil).

É interessante notar que estes conteúdos, apesar de serem citados como gerais em todos os ciclos nos planejamentos anuais, quando os professores os propõem nos planejamentos específicos de 
Ano XXI, n 32/33, junho e dezembro/2009

cada ciclo, estes aparecerem apenas para o $1^{\circ}$ ciclo.

No segundo ciclo, apenas o professor AND (32 anos - E6) fala em "conhecimento do corpo, dos movimentos e seus limites e partes do corpo". Sobre os conteúdos citados anteriormente, Neira (2006, p. 123-124) nos diz que a Educação Infantil e as primeiras séries do Ensino Fundamental têm "grande relevância na proposição das atividades que visam o desenvolvimento das habilidades básicas como: percepção, lateralidade, orientação espaço-temporal, coordenação visual e motora e esquema corporal".

Segundo o autor, a aquisição de um esquema corporal pressupõe-se conhecer a imagem do próprio corpo, saber que este corpo é parte da nossa identidade, perceber cada parte sem perder a noção de unidade. Diz ser necessário perceber os elementos do corpo em separado para depois construir a percepção de globalidade corporal (NEIRA, 2006).

Os discursos de Neira (2006) justificam a proposta dos professores de Educação Física quanto a proposição dos conteúdos psicomotores. Somados a estes conteúdos, os professores ainda sugerem o trabalho com: a atenção visual e auditiva; percepção sinestésica; memória visual, auditiva e sinestésica; associação de ideias; compreensão e raciocínio; informações sonoras, visuais e táteis.

As possibilidades de movimento do nosso corpo são inúmeras e a Educação Física tem a responsabilidade de explorar estes conhecimentos, levando o aluno a uma compreensão e reflexão sobre o corpo e seus movimentos e não apenas à prática descontextualizada dos mesmos. Neste sentido, o professor ROB (31 anos - E4) propõe a apresentação e discussão de textos sobre o "corpo humano" e "a função dos movimentos", fazendo menção à dimensão conceitual dos conteúdos.

Outros conceitos tratados pelos professores referem-se as "noções básicas sobre higiene e postura", como aparecem nos planejamentos dos professores AND (32 anos - E6) e ANE (32 anos - E3). Especificam a higiene nas aulas de Educação Física, na hora do lanche e na sala de aula, para os dois primeiros ciclos do Ensino Fundamental.

Nota-se ainda que a "postura", citada anteriormente, aparece na dimensão procedimental sempre atrelada ao "alongamento". A professora ROS sugere o alongamento como conteúdo para $5^{\circ}$ e $6^{\circ}$ anos. Já o professor AND propõe a sequência de alongamentos como conteúdo para $1^{\circ}$ ciclo e, ainda, suas definições e razões de fazêlos (conceitos) para todos os ciclos. 
Percebe-se que o alongamento é um conteúdo que causou divergência, pois não há uma unanimidade quanto ao momento em que deve ser proposto, ou seja, em qual ano deve ser contemplado.

Darido e Rangel (2005) falam da necessidade de compreender as habilidades e as capacidades necessárias à prática de atividades físicas, aprendendo estratégias para o aprendizado de novas habilidades e não somente o aprimoramento da técnica das habilidades já aprendidas. Neste sentido, veremos o que os professores de Educação Física pesquisados propõem quanto a aprendizagem das habilidades motoras e das capacidades físicas.

As habilidades motoras são propostas no planejamento de quatro professores. A professora JOS (38 anos - E4) é a única que propõe os conteúdos de habilidades motoras de estabilização para os dois ciclos. Este conteúdo é o Equilíbrio dinâmico e estático (uma perna só, aviãozinho, parada de mão, estátua).

Os demais conteúdos referentes às habilidades motoras são propostos apenas para o $1^{\circ}$ ciclo. As habilidades parecem ter sido retiradas da proposta elaborada por Tani e colaboradores (1988). Vejamos os conteúdos propostos: Habilidades de locomoção: andar, correr, saltar, desviar, rolar, girar, abaixar, levantar, contornar, subir, descer e trepar; Habilidades de manipulação (não especificados no planejamento); Habilidades de estabilização: equilíbrio; paradas abruptas e saídas também; mudança de direção; Movimentos combinados.

As habilidades de estabilização foram todas citadas pela professora JOS (38 anos - E4) e são similares ao conteúdo "domínio do corpo" - saída rápida, parada brusca e mudança de direção - elaborado por Paes (2002) em sua proposta de sistematização dos conteúdos do Esporte coletivo.

As capacidades físicas aparecem como conteúdos de ensino no planejamento de três professores participantes desta pesquisa, sendo denominadas por eles de "habilidades motoras" ou "exercícios físicos". Porém, os elementos constitutivos deste conteúdo são os mesmos propostos por autores como Freire e Scaglia (2003) como "capacidades motoras" e por Darido e Souza Júnior (2007) como "capacidades físicas".

Dentre os componentes das capacidades físicas citadas, apenas o equilíbrio não foi mencionado pelos professores. Isto se deve aos mesmos proporem o equilíbrio como uma habilidade motora de estabilização, o que também é correto.

Freire e Scaglia (2003) sugerem para este conteúdo os componentes: força, resistência, agilidade, velocidade e flexibilidade. Estes 
Ano XXI, n 32/33, junho e dezembro/2009

componentes coincidem com os sugeridos pelos professores AND, ROB e a professora ROS, aparecendo no planejamento anual como conteúdo para todos os ciclos, porém nos semanais são determinados apenas para o $1^{\circ}$ ciclo. Foi citada ainda a "capacidade respiratória", que está diretamente ligada a resistência aeróbia.

Numa relação entre conhecimento sobre o corpo e fisiologia, é proposta para todos os ciclos, na dimensão conceitual, a "explicação do sistema pulmonar - por que ficamos ofegantes? Qual a melhor forma de recuperação?" (ROB/M - 31 anos - E4).

O professor ROB é o único que cita as capacidades físicas como "componentes da aptidão física". Betti e Zuliani (2002) nos alertam que o trabalho voltado para a aptidão física só deve acontecer a partir do $8^{\circ}$ ano do Ensino Fundamental. Lembram ainda que a aprendizagem de habilidades motoras e o desenvolvimento de capacidades físicas são necessárias nas aulas de Educação Física, porém não são suficientes. Assim, a Educação Física escolar não pode resumir-se apenas nestas práticas corporais, sendo necessária a contemplação das outras dimensões do conteúdo também.

O professor ROB propõe ainda a avaliação física e funcional de peso, altura e flexibilidade, que se constitui no "diagnóstico e acompanhamento dos níveis de crescimento, composição corporal e desempenho motor", tanto no $1^{\circ}$ quanto no $2^{\circ}$ ciclo.

Ao pensar sobre o crescimento e desenvolvimento motor, comunga-se com as seguintes palavras:

Conhecer o corpo é mais do que saber quais são as suas partes e o que essas partes podem fazer. Devemos confrontar quaisquer ideologias que reduzam as possibilidades do corpo e que o fragmentem, sendo necessário compreender o processo de constante mudança que caracteriza o corpo, como ocorre seu crescimento e seu desenvolvimento (DARIDO; RANGEL, 2005, p. 140-141).

Neste sentido, o professor ROB (31 anos - E4) propõe temas de relevância social que, quando trazidos para o contexto da Educação Física na escola, se tornam conteúdos de ensino. Um conteúdo ligado ao crescimento e desenvolvimento motor é a reflexão sobre o envelhecimento do nosso corpo - Idoso ou envelhecimento sadio. O professor ROB propõe para $1^{\circ}$ e $2^{\circ}$ ciclos:

Conceitos: conhecimento do corpo humano e suas limitações; Semelhanças e diferenças do corpo idoso com os mais jovens; Atividade física e envelhecimento: benefícios 
e riscos da atividade física; Estatuto do idoso; Envelhecimento sadio: por que o corpo envelhece; Tipos de alimentação que ajudam a retardar a velhice; Orientações e seleção de exercício para idosos realizar; Principais doenças relacionadas ao idoso; Prática esportiva do idoso. Procedimentos: visita ao centro de convivência para a $3^{\text {a }}$ idade; Sequência de atividades práticas para o idoso, elaborada pelos alunos. Atitudes: responsabilidade e respeito ao idoso.

Percebe-se que a relação entre os conhecimentos sobre o corpo e o idoso é nítida nos conteúdos apresentados pelo professor ROB em seu planejamento, apesar de não fazer distinção indicativa de ano. Esta perspectiva transcende o "saber fazer" e suas razões, levando ao aluno a possibilidade de adquirir conhecimentos contextualizados e a reflexão dos mesmos.

O professor ROB faz uma relação da Educação Física com a qualidade de vida, o que interfere diretamente nos conhecimentos sobre o corpo. A "prevenção de doenças do coração, conhecimento de suas funções e prevenção de doenças degenerativas" são conceitos alcançados através da relação com a atividade física, fisiologia e hábitos de vida saudáveis. Somados a isto, a professora JOS (38 anos - E4) propõe para o $2^{\circ}$ ciclo a discussão dos "benefícios (efeitos) das atividades físicas" através de textos e pesquisas sobre "obesidade".

Numa dimensão de corpo mais social e antropológica, o professor ROB propõe a interlocução com o tema Diversidade Racial. Como conteúdos, pode-se extrair: o "estudo das etnias; diversidade cultural; semelhanças físicas; semeIhanças e diferenças raciais na sala de aula; aceitação e convivência; conscientização da cultura negra". Assim, finaliza-se o bloco de conteúdos "conhecimentos sobre corpo" ratificando que conhecer a si mesmo transcende o fazer motor expresso por habilidades motoras, capacidades físicas ou esquema corporal.

\section{"Momento recreativo": conte- údo, metodologia ou prática descontextualizada?}

Os jogos e as brincadeiras populares são conteúdos recorrentes no planejamento dos sete professores que entregaram. Em alguns momentos, os jogos e brincadeiras aparecem como instrumento para o ensino de outros conteúdos específicos, tranformando-se, neste caso, em estratégia (ou metodologia/ atividade) de ensino.

É comum na Educação Física esta estratégia, como exemplo, numa determinada aula, o conteúdo a ser ensinado pode ser a vivência de 
Ano XXI, n 32/33, junho e dezembro/2009

uma brincadeira popular da época em que os pais de nossos alunos eram crianças e que hoje são desconhecidas deles. Neste sentido, a brincadeira popular é o conteúdo da aula.

Em outra aula, pode-se propor, por exemplo, o ensino do conteúdo habilidades de estabilização, sendo utilizado para isto um jogo de pegar em que as crianças devem correr em cima de cordas e bancos estreitos, exigindo-se assim o equilíbrio. Neste caso, o jogo se tornou uma estratégia para ensinar um determinado conteúdo da Educação Física, sendo comum ouvir dos professores de Educação Física que utilizam "atividades lúdicas" ou "atividades recreativas" em suas aulas.

É preciso tomar cuidado com a compreensão internalizada por alguns professores de Educação Física de que é preciso tornar a aula lúdica, respeitando-se a espontaneidade da criança em brincar. Esta concepção traduz a proposição de aulas em que a "recreação" se constitui no seu momento principal. Porém, vê-se que este momento acaba revelando uma aula descontextualizada, em que as atividades recreativas são propostas com a finalidade precípua de divertir, sem objetivos determinados e nem conteúdos a serem ensinados. Apenas o brincar por brincar.

Dos professores que entregaram planejamentos semanais, nos quais pode-se analisar o que foi oferecido aula a aula, dois professores apresentaram nos planos de aula os termos "momento recreativo", "atividades recreativas" ou simplesmente "recreação". Como estes professores não descreviam claramente todos os passos de um plano de aula, ou seja, às vezes não deixavam claro o conteúdo a ser ensinado na aula, teve-se que tentar compreender o contexto em que se inseriam os termos mencionados anteriormente. Será que se referiam ao ensino de jogos ou brincadeiras como conteúdo? Será que se constitui apenas em atividades propostas para ensinar determinado conteúdo, ou seja, uma estratégia de ensino? Ou apenas momento de diversão nas aulas de Educação Física?

No planejamento do professor ROB (31 anos - E4) pode-se identificar o "momento recreativo" representativo das três condições anteriores: ora como conteúdo, ora como método de ensino, ora como mera recreação.

O momento recreativo ou parte recreativa da aula indicada pelo professor ROB em seu planejamento se caracteriza como uma mera recreação quando propõe atividades (no caso, brincadeiras/ jogos) sem relação alguma com o objetivo ou conteúdo proposto na aula. Tem-se a impressão da necessidade das aulas de Educação Física 
em oferecer uma parte prática em suas aulas, levando o professor a destinar uma parte de sua aula à práticas descontextualizadas, recreativas, ou seja, atividades sem intenção pedagógica, mas divertidas.

Por exemplo, no planejamento semanal do professor ROB, ele propõe uma aula cujo tema é o "idoso e suas qualidades" e o objetivo da aula é "mostrar para os participantes a responsabilidade do respeito e as semelhanças e diferenças do corpo em relação aos mais jovens" (ROB/M - 31 anos - E4). Neste sentido, propõe num primeiro momento da aula atividades para desenvolver o tema em questão, como a discussão sobre as principais doenças relacionadas ao idoso e os exercícios físicos adequados a eles. O professor não indica para qual ciclo propõe esta aula.

A segunda parte desta mesma aula é nomeada de "parte recreativa", em que o professor propôs atividades como "gato e rato", "nunca três", etc. Em outra aula, desta vez para a Educação Infantil, o planejamento não destaca o conteúdo da aula e nem os objetivos, apenas atividades, sem ligação ou coerência entre elas.

Estes exemplos são características da concepção de recreacionismo, em que se enfatiza a ideia de ações ao ar livre, sejam elas organizadas ou não. Sobre o recreacionismo, Waichman (2004, p.26) diz que não há um interesse profundo pelas atividades além do seu "emprego no tempo desocupado. O importante é disponibilizar uma oferta larga de possibilidades, desde a atividade gratuita (uso de lugares públicos ao ar livre) até jogos sofisticados e onerosos".

Esta concepção é diferente da abordagem recreacionista em que aparece a figura do professor "rola bola". No caso dos nossos exemplos, a recreação se caracteriza simplesmente por oferecer a diversão através de jogos e brincadeiras escolhidas. É como se o professor abrisse um livro e selecionasse as atividades "mais legais" para aquela aula, sem objetivo e/ou conteúdo determinado. Esta prática é muito comum entre os professores de Educação Física, que entendem a disciplina, principalmente para a Educação Infantil e $1^{\circ}$ ciclo, como uma prática lúdica.

A recreação aparece no planejamento do professor ROB e da professora ROS também como um procedimento utilizado para ensinar outros conteúdos. Numa aula da professora ROS, por exemplo, o conteúdo expresso nos objetivos corresponde a "percepção visual, auditiva, atenção, capacidade respiratória e coordenação motora fina" (ROS/F - 39 anos - E1). As atividades propostas para o $2^{\circ}, 3^{\circ}$ 
Ano XXI, n 32/33, junho e dezembro/2009

e $4^{\circ}$ ano são descritas da seguinte forma: 1- Atividade para despertar a atenção: corrida de formação de grupos, corrida dos números e "dentro e fora". 2- Recreação: a ponte e coelhinho sai da toca.

Percebe-se que esta aula proposta pela professora ROS apresenta a recreação como um procedimento de ensino para ensinar os conteúdos pré-determinados. É nítido em suas aulas esta divisão nas atividades propostas, sempre oferece exercícios ou parte teórica no início da aula e, logo após, jogos e brincadeiras para ensinar conteúdos. O professor ROB também destaca em seu planejamento a recreação como procedimento de ensino, e ainda nomeia de "método recreativo".

E a recreação enquanto conteúdo da Educação Física? Não se considerou a recreação como um conteúdo, porém o tratamento dado pelos professores pesquisados a este termo, associando-o aos jogos, supõe-se como um conteúdo. Neste caso, os professores utilizam o termo "jogos recreativos", "recreação" ou apenas "jogos" para dizer que o conteúdo de ensino são os jogos propriamente ditos, ou como nos indica Darido e Rangel (2005), "jogos reproduzidos".

O ensino de jogos na perspectiva de reprodução só não aparece no planejamento do pro- fessor CIN. Para os demais, este conteúdo é proposto para os dois ciclos iniciais do Ensino Fundamental, sem distinção nenhuma do conteúdo entre os ciclos. Ainda, é apresentado apenas na dimensão procedimental, o saber fazer. Nesta dimensão inclui-se também "as regras dos jogos", proposto pelo professor ROB para o $2^{\circ}$ ciclo. Em apenas um planejamento, da professora JOS, é citado a "organização de jogos e regras" ( $2^{\circ}$ ciclo), fazendo menção às atitudes dos alunos diante destes jogos.

Sobre as dimensões conceituais e atitudinais, estas aparecem ligadas ao conteúdo "jogos cooperativos" — único a apresentar as três dimensões do conteúdo. No conteúdo "jogos de salão", a dimensão atitudinal e procedimental são destacadas no planejamento, mas desta vez apenas despida de fatos ou conceitos. Vejamos então estes conteúdos: Jogos cooperativos: O que é cooperação: conceitos e conhecimentos dos alunos; Importância da cooperação (textos); Jogos cooperativos: vivência de jogos propostos pelo professor e escolhidos pelos alunos; recreação semi-cooperativa; cooperação, socialização, respeito, coletividade, confiança no outro e relação interpessoal.

Os professores AND (32 anos - E6) e JOS (38 anos - E4) propõem estes jogos para os dois ciclos 
do Ensino Fundamental, inclusive a "importância dos jogos cooperativos" através de textos aparece no planejamento da professora JOS para o $1^{\circ}$ ciclo. Mas será que os alunos do $1^{\circ}$ ciclo têm condições de ler textos e compreender a importância da cooperação? O professor ROB, por exemplo, só propõe os jogos cooperativos a partir do $2^{\circ}$ ciclo.

Brotto (2001) considera que para a integração dos Jogos Cooperativos em grupos ou ambientes com pouca ou nenhuma experiência anterior é aconselhável iniciar pelos jogos semi-cooperativos - recreação semi-cooperativa como propôs o professor ROB anteriormente - e gradativamente caminhar na direção dos jogos cooperativos sem perdedores.

Ao refletir sobre a escola, a assertiva anterior de Brotto (2001) é pertinente se pensarmos nas características de crianças de $1^{\circ}$ ciclo, que segundo Piaget (s.d., citado por FREIRE, 2005) é neste período, entre 6 e 7 anos, que a criança começa a ser capaz de cooperar. É nesta fase também que a criança começa a se interessar por jogos sociais, deixando o egocentrismo de lado.

Baseando-se nesses autores, entende-se que as crianças de $1^{\circ}$ e $2^{\circ}$ ano ainda estão neste período de transição entre o egocentrismo e a socialização, sendo ainda incapazes de cooperar. Talvez, por começarem a entrar na fase de raciocínio lógico (PIAGET, s.d, apud FREIRE, 2005), elas são capazes de entender a importância de cooperar com os colegas, mas isso não quer dizer que ela terá atitudes de cooperação num jogo. Socialização sim, mas não cooperação. Talvez a proposta do professor ROB em oferecer os jogos cooperativos a partir do $2^{\circ}$ ciclo corrobora com a discussão anterior.

Os jogos de salão, de mesa ou de tabuleiro é outro conteúdo presente no planejamento dos professores pesquisados, apresentado com exclusividade pela professora CID (52 anos - E2). Nesta escola em especial, por conta da inexistência de um espaço adequado às aulas de Educação Física, a professora ocupa a sala de aula oferecendo este conteúdo aos alunos como eixo norteador de seu trabalho, juntamente com jogos intelectivos ou de raciocínio lógico.

Na dimensão atitudinal, são apresentados os seguintes conteúdos pela professora CID: a criatividade, atenção, cooperação, criação de regras, respeito ao colega e cumprimento de regras. Acrescentando, a professora JOS (38 anos - E4) sugere para os jogos de mesa, a participação, formação de grupos, troca de material e acordo com as afinidades. A professora CID esboça ainda uma sistematização dos mesmos para cada ano do $2^{\circ}$ ciclo. Vejamos estes conteúdos no quadro 1 : 
Ano XXI, n³2/33, junho e dezembro/2009

Quadro 1: Conteúdos dos jogos de salão e intelectivos para o $2^{\circ}$ ciclo.

\begin{tabular}{|c|c|c|c|c|}
\hline \multicolumn{2}{|c|}{$4^{\circ}$ e $5^{\circ}$ anos } & \multicolumn{3}{|c|}{$6^{\circ}$ ano } \\
\hline $\begin{array}{l}\text { Palavras } \\
\text { cruzadas } \\
\text { diretas } \\
\text { Dama } \\
\text { Quebra- } \\
\text { cabeça }\end{array}$ & $\begin{array}{l}\text { Jogo da } \\
\text { memória } \\
\text { Sequência } \\
\text { lógica } \\
\text { Lego }\end{array}$ & $\begin{array}{l}\text { Confecção de } \\
\text { jogo de ludo } \\
\text { Quebra-cabeça e } \\
\text { jogo da memória } \\
\text { Torneio de } \\
\text { damas }\end{array}$ & $\begin{array}{l}\text { Conteúdos } \\
\text { atitudinais: } \\
\text { criatividade } \\
\text { cooperação } \\
\text { atenção }\end{array}$ & $\begin{array}{l}\text { respeito ao } \\
\text { adversário e às } \\
\text { regras de } \\
\text { competitividade }\end{array}$ \\
\hline
\end{tabular}

Baseado no planejamento da professora CID/F - 52 anos - E2.

A professora JOS sugere ainda o "bozó" como um conteúdo dos jogos de mesa. No planejamento do professor ROB aparece o "tênis de mesa" para os dois ciclos, classificado por ele como um jogo, assim como Araújo (2004) o classifica.

A professora JOS sugere para o $1^{\circ}$ ciclo os “jogos de mímica, atividades historiadas e pequenos jogos". Os jogos chamados de imitação ou ficção se relacionam com o simbolismo, à imitação ou à imaginação. Estes jogos são considerados por Araújo (2004) vinculados aos jogos simbólicos classificados assim por Piaget. Assim, pode-se considerar a mímica como uma imitação e as atividades historiadas ligadas a imaginação, ou seja, conteúdos ligados aos jogos simbólicos.

Freire e Scaglia (2003), em sua "distribuição de temas pelas diversas séries", recomendam os jogos simbólicos da Educação Infantil até a $1^{\text {a }}$ série, que no nosso caso corresponde até o $2^{\circ}$ ano do Ensino Fundamental. Os autores indicam os jogos simbólicos até a primeira série porque, "as crianças ainda vivem fortemente o período das fantasias, da organização das representações mentais. Portanto, elas precisam de atividades que fomentem o desenvolvimento de tais funções" (FREIRE; SCAGLIA, 2003, p. 38). Logo, devemos refletir apenas se estes conteúdos propostos pela professora JOS ao $1^{\circ}$ ciclo serão eficientes e interessantes para as crianças de $3^{\circ}$ ano, que ainda se encaixam no $1^{\circ}$ ciclo.

\section{As Brincadeiras Populares}

Nas brincadeiras populares, "as crianças se engajam em regras testadas por séculos, que são 
passadas de criança para criança sem nenhuma referência à escrita, parlamento ou a alguma propriedade adulta." (OPIE; OPIE, 1976, apud PONTES; MAGALHÃES, 2003, p. 122).

Araújo (2004) diz que as brincadeiras perpassam o tempo, de geração a geração. A estes se vincula a cultura de jogos infantis tradicionais, que são conhecidos, entre outras denominações, como jogos de rua e brincadeiras populares. Ao trabalhar com esta categoria de jogos, podem ser consideradas e discutidas as características regionais e as mudanças que os jogos sofrem de acordo com o contexto de cada região. A autora reforça que um dos aspectos do comportamento que julga importante ser evidenciado durante a realização desses jogos é o aspecto sócio-cultural.

Estes aspectos descritos anteriormente são importantes para diferenciarmos jogos (reproduzidos ou de regras) de brincadeiras populares, pois nem sempre os professores deixam claro em seus planejamentos que estão se referindo as brincadeiras, ou seja, às vezes os conteúdos referentes a este bloco não estão explícitos e sim imbricados no conteúdo de jogos. No planejamento dos sete professores de Educação Física, apenas a professora CID não faz menção às brincadeiras populares.

A professora ROS (39 anos -E1) elenca brincadeiras que devem ser trabalhadas com as crianças de $1^{\circ}$ ciclo, como a amarelinha, pular corda, bambolê, bolinha de gude, pipas, lenço atrás, corre cotia, esconde-esconde, coelho sai da toca, duro ou mole, tourinho, reloginho, pega-pega, bom barqueiro, corrida dos panos, gato e rato, cordeirinho e lobo. Percebe-se que são brincadeiras tradicionais infantis, introduzidas nas aulas de Educação Física como um conteúdo procedimental.

O professor ROB indica o trabalho com as "brincadeiras esquecidas dos alunos" (antigas) para o $1^{\circ}$ e $2^{\circ}$ ciclos. O professor AND (32 anos - E6) oferece no $3^{\circ}$ bimestre "oficinas para confecção de brinquedos" (projeto arte reciclada). A professora ANE (32 anos - E3) também propõe a construção de brinquedos, mais especificamente a "confecção de petecas e suas formas de jogar" e, na dimensão conceitual, "história da peteca - como os índios brincavam de peteca".

As brincadeiras de roda ou brincadeiras cantadas estão presentes no planejamento de quatro professores e são indicadas para todos os anos, com exceção da professora ROS que oferece este conteúdo apenas para o $1^{\circ}$ ciclo.

Partindo do pressuposto que as brincadeiras de roda ou cantadas são formas de representação da cultura tradicional infantil, 
Ano XXI, n 32/33, junho e dezembro/2009

carregadas de valores culturais que devem ser conservados, discutidos e transmitidos a outras gerações, pode-se considerar este conteúdo como parte do bloco de conteúdos "Brincadeiras Populares", como fizeram os professores de Educação Física anteriormente.

Sobre a dimensão conceitual das brincadeiras populares, França e Grando (2007) compreendem a possibilidade de, a partir delas, trabalhar a história de uma cidade/estado/país e a história da infância nestes locais, oportunizando, no contexto escolar, a organização de saberes da realidade da qual as crianças participam, com historicidade e valorização das mais diversas formas de viver. Talvez sejam estes os conteúdos não identificados nos planejamentos, porém relevantes e necessários à Educação Física.

\section{O ritmo e expressão corporal}

Neste bloco de conteúdos reuniram-se as atividades rítmicas e expressivas e as danças, partindo-se do micro para o macro, ou seja, do regional para o nacional, das danças tradicionais cuiabano/matogrossenses para as demais danças recorrentes nos planejamentos dos professores. E, a partir daí, serão apresentados o que propõem sobre atividades rítmicas e expressivas.
Dentre as danças tradicionais cuiabanas, as mais conhecidas são o cururu, siriri e rasqueado, que são lembrados pelos professores ANE/F (32 anos - E3) e AND/M (32 anos - E6) em seus planejamentos. Propõem como conteúdos da Educação Física para todos os anos do $1^{\circ}$ e $2^{\circ}$ ciclo "as danças regionais de Cuiabá, o rasqueado e o siriri", e na dimensão conceitual "a cultura de Mato Grosso e as danças típicas de Cuiabá".

A festa junina também traz conteúdos que são propostos por três professores em suas aulas, como a "dança da quadrilha" e atitudes como "participação na festa junina". Estes conteúdos são propostos para todos os anos dos ciclos pesquisados, porém os professores não apresentam maiores detalhes do assunto, não sendo possível identificar se a festa junina é trabalhada contextualizada dentro de um bloco de conteúdo de danças, ou se constitui apenas numa obrigação de ensaiar quadriIhas para a festa da escola.

Em relação às danças tradicionais do Brasil, o professor ROB propõe para os dois ciclos, na dimensão conceitual, "as danças e comidas típicas das regiões do Brasil" e, especificamente para o $5^{\circ}$ ano, dentro da temática Diversidade Racial (cultural), "pesquisa sobre danças do Brasil - forró, pagode, 
axé e capoeira - onde nasceram, de quais regiões são e se são conhecida no Brasil".

A professora JOS indica para todos os anos a dança de "maculelê enfocando o respeito às origens e formas de dançar de cada país". Sistematizadas as "danças folclóricas": "danças de roda e rodas contadas" para $1^{\circ}$ ciclo, e "danças circulares de diversos países e dança sênior" para $2^{\circ}$ ciclo.

A dança circular e os brinquedos cantados (e cantigas de roda) aparecem também no planejamento do professor AND. Como também a professora ROS (39 anos - E1) fala em cantigas folclóricas ( $1^{\circ}$ ano), musiquetas folclóricas e brincadeiras cantadas - escravos de Jó $\left(2^{\circ}\right.$ ao $\left.4^{\circ}\right)$, e danças $\left(5^{\circ}\right.$ e $6^{\circ}$ anos), sugerindo uma organização destes conteúdos para cada ano do Ensino Fundamental.

Vimos no item sobre as brincadeiras populares a citação de alguns destes conteúdos (brincadeiras cantadas, músicas folclóricas, etc.) assim classificados pelos professores de Educação Física. Porém, concordo com Toledo (2006, p. 78) que afirma "as cantigas e as rodas cantadas são consideradas parte dos conteúdos Dança e Atividades Rítmicas e Expressivas".

A diferença das rodas cantadas para as cantigas é que estas podem ser cantadas em roda, mas não se caracterizam como rodas cantadas. Sobre as atividades rítmicas e expressivas, envolvem atividades que relacionam a música ao movimento, assim como a interpretação e o processo criativo de ações coreográficas (TOLEDO, 2006).

Percebe-se que a Capoeira foi relacionada pelos professores ROB e JOS como uma dança. Porém, recomenda-se considerá-la como um bloco de conteúdos a parte, que será discutido adiante.

Outros conteúdos trabaIhados pelos professores de Educação Física neste bloco são: movimento do corpo através da dança; coreografias simples (músicas - lateralidade); movimento dos animais; danças expressivas (sentimentos); atividades rítmicas: deslocamento no ritmo da música, agrupamentos com ritmos diferentes, dança das cadeiras, ritmos de diferentes países; danças coreografadas - atividades lúdicas com e sem instrumentos.

Os conteúdos acima são descritos para $1^{\circ}$ e $2^{\circ}$ ciclos, sem especificação de anos e nem detaIhamentos sobre o significado dos mesmos ou exemplos de como trabalhá-los. O mesmo ocorre com a professora CID que propõe, especificamente para o $2^{\circ}$ ciclo, os seguintes conteúdos: formas naturais primárias e secundárias com e sem elementos; formas rítmicas de movimentos axiais com e sem elementos; 
Ano XXI, n 32/33, junho e dezembro/2009

associação de várias formas rítmicas de movimentos axiais.

\section{A capoeira}

Falcão (2006, p. 59) nos diz que a "capoeira pode ser vista como um misto de jogo, arte, luta, dança e folclore que vem, sistematicamente, se incorporando à lógica desportiva, a partir de várias iniciativas de cunho oficial e privado". O autor considera a capoeira como uma "construção social que extrapola conotações específicas que tentam acomodá-la em dimensões fechadas".

Como foi visto anteriormente, os professores de Educação Física consideram a capoeira como uma manifestação da dança, o que é verdade. Porém, a capoeira tem outras características que não permitem que a classifiquemos apenas em um bloco de conteúdos, sendo necessário assim considerá-la um conteúdo a parte.

No planejamento dos professores pesquisados, apenas dois sugerem a capoeira como conteúdo da Educação Física, e mesmo assim apenas o professor ROB o explicita com mais detalhes. Ele alude na dimensão conceitual o "início, histórico e qualidades físicas trabalhadas na capoeira". Na procedimental, a "ginga simples e principais golpes da capoeira". A dimensão atitudinal não é lembrada em seu planejamento. Estes conteúdos não aparecem ligados a nenhum ano do Ensino Fundamental, sugerindo o trabalho com todos os ciclos. Porém, estão vinculados ao tema "diversidade racial", proposto pelo professor ROB.

Souza e Oliveira (2001) ressaltam a relevância deste conteúdo nas aulas de Educação Física na escola, e como foi possível verificar, é pouco trabalhado pelos professores pesquisados nos anos iniciais do Ensino Fundamental. Os autores sugerem em seu texto uma estruturação da capoeira para as diferentes fases de ensino na escola, elencando conteúdos distintos para os anos inicias e finais do Ensino Fundamental e ensino médio.

\section{A Ginástica}

A ginástica, como conteúdo da Educação Física, está presente no planejamento de quatro professores, dentre os sete que entregaram este documento. A professora ANE (32 anos - E3) não especifica quais são os conteúdos da ginástica trabalhados por ela, apenas fala em "ginástica", sem exemplos ou maiores detalhes.

A ginástica é proposta exclusivamente na dimensão procedimental pelos professores pesquisados. Faz-se necessário relembrar que a ginástica como conteúdo da 
Educação Física - e isso serve para todo e qualquer conteúdo específico - não deve resumir-se ao "saber fazer", a mera execução de técnicas. Como nos alerta Neira (2006), o exercício e a técnica não substituem a aprendizagem, que só será possível pela compreensão da situação-problema e da consciência mais ou menos clara que orienta a intencionalidade da ação. Ou seja, não basta fazer, é preciso compreender.

O professor ROB (31 anos - E4) indica em seu planejamento anual, para todos os anos, o que ele nomeia de "ginástica recreativa", fazendo menção a ginástica rítmica, olímpica (artística) e as capacidades físicas. Sobre a ginástica recreativa, faz referência a alguns fundamentos da Ginástica Artística como parada de três apoios, rolamentos (cambalhota), avião e apoio fixo na parede. Percebe-se que é uma característica do professor ROB em atrelar o termo recreativo aos conteúdos propostos, como fez com os jogos e brincadeiras, e com os esportes (mais adiante). Fica a impressão de que o termo recreativo serve para denotar algo que não é formal, mas lúdico, legal, destinado ou adaptado às crianças.

Assim, o professor ROB dedica aos $1^{\circ}$ e $2^{\circ}$ anos o conteúdo de "ginástica acrobática", propondo ainda rolamentos e cambalhotas, movimentação com três apoios, paradas com apoio na parede, elefantinho, etc. Os fundamentos propostos pelo professor ROB para a ginástica recreativa e acrobática são praticamente os mesmos, sugerindo o trabalho com o que Toledo (1999) nomeia de elementos ginásticos, ou seja, movimentos que são criados a partir das habilidades naturais do ser humano (andar, correr, saltar, girar, etc.) caracterizado-se pela existência de uma técnica própria. Estes elementos são obrigatórios na ginástica artística. Neste sentido, a professora ROS (39 anos - E1) trabalha com o $1^{\circ}$ ciclo as formas básicas de ginástica - andar, correr, saltar e rastejar -, e cambalhotas no colchão.

Toledo (1999), em sua dissertação de mestrado, propõe uma sequência para o aprendizado dos conteúdos da ginástica nas três dimensões do conteúdo, baseado em Coll. Na dimensão procedimental propõe uma sequência de conteúdos (ou hierarquia) a serem ensinados na escola. Os conteúdos propostos pelos professores corroboram com a segunda etapa proposta por Toledo (1999), ou seja, elementos constitutivos da ginástica e a combinação entre eles. O próximo passo é o que o professor AND propõe a seguir sobre os conteúdos da GA especificamente. Estes aparecem novamente no $3^{\circ}$ bimestre - lembrando que ele os 
Ano XXI, n 32/33, junho e dezembro/2009

menciona no $2^{\circ}$ bimestre também, mas desta vez os elementos da GA são propostos em "sequências ginásticas" diferentes para cada ano do Ensino Fundamental. Vejamos o que ele propõe para cada ano: $1^{\circ}$ ano: rolamento para frente, vela, avião e pose; $2^{\circ}$ e $3^{\circ}$ anos: rolamento para trás, avião, meio giro, rolamento para frente, vela, pose "ajoelhada" e pose final em V; $4^{\circ}$ e $5^{\circ}$ anos: avião, rolamento para frente, vela, puxada, rolamento pra trás, salto grupado, salto em reversão com finalização em avião, giro $360^{\circ}$ com salto e pose.

A sequência ginástica proposta pelo professor AND sugere uma sistematização do conteúdo procedimental da GA, pois se entende que para a efetivação de cada sequência os alunos precisam conhecer cada elemento (fundamentos) da GA. Neste sentido, subentende-se que o professor já havia oferecido estes conteúdos aos seus alunos anteriormente, e os elementos propostos seguem uma lógica de aprendizagem, a medida que no $1^{\circ}$ ano contempla menos elementos e com grau de dificuldade "fácil" até chegar ao $5^{\circ}$ e $6^{\circ}$, com maior número de elementos ginásticos, englobando todos os anteriores.

A ginástica rítmica, apesar de citada pelo professor ROB, não é apresentada em detalhes por nenhum professor. A Ginástica apa- rece no planejamento da professora ROS (39 anos - E1) sob três formas diferentes: de manutenção da saúde (aeróbica); de preparação e aperfeiçoamento para dança; de preparação para os esportes coletivos.

Estas formas de ginástica, apesar de serem apresentadas no planejamento anual, não foram oferecidas durante o ano letivo pela professora ROS constatado em análise dos planos de aula. Não se sabe o motivo que levou a professora a não desenvolver este conteúdo, mas segundo Schiavon e Nista-Piccolo (2006) a ginástica, como conteúdo de ensino, é pouco (ou inexistente) trabalhada nas escolas. Este fato é atribuído a falta de materiais específicos, deficiências de espaços adequados a esta prática e falhas na formação profissional.

\section{Os esportes coletivos e o atletismo}

O bloco de conteúdos "esporte" só não está presente no planejamento da professora CID, tendo um espaço reservado no trabalho dos outros seis professores que entregaram os planejamentos. Os esportes coletivos (voleibol, basquetebol, handebol e futsal) ganham destaque neste bloco de conteúdos, pois são as únicas manifestações esportivas contempladas por estes professores, constando nos 
seis planejamentos citados, salvo as professoras JOS e ROS que, além dos esportes coletivos, destacam o atletismo.

Iniciando pelo atletismo, ou seja, único esporte individual citado pelos professores, os conteúdos propostos são apresentados apenas na dimensão procedimental e mesmo assim de forma muito restrita. A professora JOS/F (38 anos -E4) propõe para todos os anos do $1^{\circ}$ e $2^{\circ}$ ciclos a "variação dos saltos em altura e distância".

A professora ROS/F (39 anos - E1) apresenta para o $1^{\circ}$ ciclo as "corridas de velocidade, resistência, com obstáculos e de revezamento". No segundo ciclo o atletismo não é citado em nenhum momento. Percebe-se que o atletismo é pouco trabalhado nas aulas de Educação Física dos professores pesquisados, sendo contemplados apenas as corridas e saltos, lembrando que as modalidades do atletismo se constituem ainda por arremessos, lançamentos e marchas.

Sobre os esportes coletivos, é possível observar nos planejamentos dos professores alguns conteúdos comuns às quatro modalidades e outros conteúdos específicos a elas. Os conteúdos comuns são: manipulação de bola - agarrar, girar com a bola, saltar, etc.; jogos pré-desportivos; iniciação desportiva: passes baixo, ombro, peito, parabólicos, etc.; gincanas esportivas e culturais: competições com a participação de todos os alunos.

Para $4^{\circ}$ e $5^{\circ}$ anos, o professor AND propõe: noções dos esportes coletivos: condução, passes, toques e arremessos; mini-jogos: equipes e tempos reduzidos; jogos interclasses para todos os anos.

Os conteúdos acima são apresentados para todos os anos do $1^{\circ}$ e $2^{\circ}$ ciclos. Apenas o professor CIN/M (55 anos - E5) faz distinção de ciclos, no qual os jogos pré-desportivos são oferecidos apenas para o $1^{\circ}$ ciclo. Ainda, este professor tem o esporte como conteúdo exclusivo das suas aulas de Educação Física.

O professor AND/M (32 anos - E6) propõe as "regras, equipamentos utilizados em cada modalidade e locais para a prática destes esportes", fazendo alusão aos conteúdos conceituais. O professor $\mathrm{CIN}$ sugere que as regras das modalidades esportivas sejam apresentadas apenas ao $2^{\circ}$ ciclo, acrescentando a discussão sobre "práticas esportivas saudáveis".

O professor ROB fala nas "diferenças entre esporte competitivo e recreativo", e a professora ROS adiciona o "espírito esportivo - derrota e vitória", que por sinal, é o único conteúdo proposto que se liga a dimensão atitudinal.

Sobre os conteúdos específicos para cada esporte coletivo, 
Ano XXI, n 32/33, junho e dezembro/2009

além do "jogo propriamente dito" e "pré-desportivo" de cada modalidade, verifica-se que apenas o voleibol traz conteúdos mais detalhados pelos professores, apesar de ser proposto a partir do $2^{\circ}$ ciclo. $\mathrm{Na}$ dimensão conceitual, o professor ROB fala da "origem, característica funcional, fundamentos, maiores campeões do mundo e as formas de jogar voleibol". Na dimensão procedimental, sugere o "aprimoramento dos movimentos e qualidades físicas; o primeiro fundamento: saque; jogos reduzidos: $3 \times 3,4 \times 4$, etc." e, especificamente para $3^{\circ}, 4^{\circ}, 5^{\circ} \mathrm{e}$ $6^{\circ}$ anos, o "voleibol cooperativo, toque e manchete".

O professor CIN especifica os conteúdos do basquetebol para o $2^{\circ}$ ciclo em "passes alto, baixo e peito; drible e arremesso". Para o futsal, o professor propõe "passes, chutes, dribles e condução". A professora ROS oferece o futsal também para o $1^{\circ}$ ciclo, na forma "jogo recreativo", subentendo-se na leitura de seu planejamento que esta prática se refere ao "deixar jogar", "dar a bola" aos alunos.

O handebol, apesar de citado pelos professores de Educação Física pesquisados, não aparece em registros de nenhum conteúdo específico ligado à modalidade e nem mesmo de atividades propostas, o que me leva a crer que não é oferecido pelo professores em suas aulas.

\section{Considerações finais}

Na configuração da proposta de sistematização dos conteúdos segundo os professores pesquisados, percebeu-se que os conteúdos, de modo geral, atendem as três dimensões do conteúdo e, quando agrupados todos estes saberes produzidos pelos professores, é possível verificar uma diversificação dos conteúdos atendendo a todos os blocos propostos nesta pesquisa.

O conteúdo de lutas não apareceu no planejamento de nenhum dos professores pesquisados, pois alegaram em depoimentos que este conteúdo poderia gerar/incentivar a violência entre os alunos, ficando aqui a indicação para inclusão do conteúdo de lutas na escola.

A sistematização de conteúdos apresentada nesta pesquisa expõe trabalhos organizados e diversificados já consolidados na escola, mas também descortina realidades que precisam ser modificadas. E, quando se une todos estas práticas num só trabalho, verifica-se a complementaridade que os conteúdos propostos por determinado professor pode contribuir para a prática dos demais, completando-se, melhorando-se, trazendo uma identidade para a Educação Física na escola. 


\section{REFERÊNCIAS}

ARAÚJO, K. de T. Os jogos sob diferentes vertentes: para além do ensino de Educação Física. Terra e Cultura, ano XX, $n^{\circ} 38$. Londrina: Unifil, jan. a jun. de 2004, p. 25-36. Disponível em: http://web.unifil.br/docs/revista_ eletronica/terra_cultura/38/Terra Cultura_38.pdf\#page $=34$

BETTI, M.; ZULIANI, L. R. Educação Física escolar: uma proposta de diretrizes pedagógicas. Revista Mackenzie de educação física e esportes. Ano 1, $\mathrm{n}^{\circ}$ 1, p. 7381, 2002.

BRASIL. Lei de Diretrizes e Bases da Educação Nacional. (LEI $n^{\circ}$ 10.793/2003). Brasília, 2003. BRASIL. Lei de Diretrizes e Bases da Educação Nacional. (LEI n 9.393/96). Brasília, 1996.

BROTTO, F. O. Jogos cooperativos:

o jogo e o esporte como um exercício de convivência. Santos SP: Projeto Cooperação, 2001. COLL, C. e colaboradores. Os conteúdos na reforma: ensino aprendizagem de conceitos, procedimentos e atitudes. Porto Alegre: Artes Médicas, 2000.

DARIDO, S. C.; SOUZA JÚNIOR, O. M. Para ensinar Educação Física: possibilidade de intervenção na escola. Campinas, SP: Papirus, 2007.
DARIDO, S. C; RANGEL, I. C. A. Educação Física na escola: implicações para a prática pedagógica. Rio de Janeiro: Guanabara Koogan, 2005.

FALCÃO, J. L. C. Unidade Didática 2: Capoeira. In: KUNZ, E. (Org.). Didática da Educação Física 1. 4 Ed. Ijuí: Unijuí, 2006. p.55-94. FRANÇA, E. S.; GRANDO, B. S. O jogo na história: maneiras de ser menino e menina entre 1945 a 1965 em Cáceres-MT. In: Corpo e cultura: tradições e saberes da cultura mato-grossense. GRANDO, B. S. (org.). CáceresMT: Editora Unemat, 2007, p. 129-148.

FREIRE, J. B. Educação de corpo inteiro: teoria e prática da educação física. $4^{\mathrm{a}} \mathrm{Ed}$. São Paulo: Scipione, 2005.

FREIRE, J. B; SCAGLIA, A. J.

Educação como prática corporal. [Pensamento e ação no magistério]. São Paulo: Scipione, 2003.

LIBÂNEO, J. C. Didática. São Paulo, Cortez: 1994.

NEIRA, M. G. Ensino de educação física. São Paulo: Thomson Learning, 2007.

Educação física: desenvolvendo competências. 2 ed. São Paulo: Phorte, 2006. PAES, R. R. A pedagogia do esporte e os jogos coletivos. In: ROSE $J R, D$. de. Esporte e atividade 
Ano XXI, n 32/33, junho e dezembro/2009

física na adolescência: uma abordagem multidisciplinar. Porto Alegre: Artmed, 2002. p.89-98.

PONTES, F. A. R; MAGALHÃES, C. M. C. M. A Transmissão da Cultura da Brincadeira: algumas Possibilidades de Investigação. In: Psicologia: Reflexão e Crítica, 2003, p. 117-124. Disponível em: http://www.scielo.br/pdf/ prc/v16n1/16803.pdf

SCHIAVON, L. M.; NISTA-PICCOLO, V. L. Desafios da ginástica na escola. In: MOREIRA, E. C. (org.). Educação física escolar: desafios e propostas 2. Jundiaí, SP: Fontoura, 2006. p.35-60.

SOUZA, S. A. R; OLIVEIRA, A. A. B. Estruturação da capoeira como conteúdo da educação física no ensino fundamental e médio. Revista da Educação Física/ UEM. Maringá, v. 12, n. 2, p. 43-50, 2. sem. 2001.

TANI, G. e colaboradores. Educação Física Escolar: fundamentos de uma abordagem desenvolvimentista. São Paulo: EPU: Editora da Universidade de São Paulo, 1988.

TOLEDO, E. O folclore na escola: um esquecido, porém precioso, conteúdo da Educação Física. In: MOREIRA, E. C. (org.). Educação física escolar: desafios e propostas 2. Jundiaí, SP: Fontoura, 2006. p. 61-86.

. Proposta de conteúdos para a ginástica escolar: um paralelo com a teoria de Coll. Dissertação (mestrado em educação física). Campinas: Unicamp - Faculdade de Educação Física, 1999. 215p.

WAICHMAN, P. A. A respeito dos enfoques em recreação. In: Revista da Educação Física/ UEM. Maringá, v. 15, n. 2, p. 22-31, 2. sem. 2004.

ZABALA, A. A prática educativa: como ensinar. Porto Alegre: Artmed, 1998.

Recebido: Abril/2010 Aprovado: Agosto/2010 